International Journal of Instruction e-ISSN: 1308-1470 • www.e-iji.net

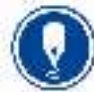

Article submission code: 20200413053331
Received: $13 / 04 / 2020$

Revision: 08/11/2020
April 2021 • Vol.14, No.2

p-ISSN: 1694-609X

pp. $969-986$

Accepted: $30 / 11 / 2020$

OnlineFirst: 18/03/2021

\title{
The Impacts of Task-based Instruction on Students' Grammatical Performances in Speaking and Writing Skills: A quasi-experimental study
}

\section{Vu Phi Ho Pham}

Assoc. Prof., Van Lang University, Vietnam, ho.pvp@vlu.edu.vn

\section{Thi Huyen Do}

Van Lang University, Vietnam, huyen.dt@vlu.edu.vn

\begin{abstract}
Previous research studies were successful in employing Task-based instruction (TBI) to enhance students' either speaking or writing skills or grammar knowledge. However, few research studies have investigated whether the TBI impacts students' grammatical performance in both speaking and writing skills. The quasiexperimental research investigated the impacts of two instructional methods between presentation, practice, production (PPP), and Task-based instructions (TBI) to see if there are any differences in improving students' productive skills. To answer the two research questions, data from the pre-test and post-test and the interviews were collected. One group was trained to learn Grammar with PPP, and the other was with TBI methods. The findings indicate that the TBI model had great impacts on students' grammatical performances in speaking and writing skills, but it was not outperformed the PPP instruction. However, the TBI model's employment was recommended to the language teachers because it created many opportunities for the students to practice the language in the grammar classrooms, and the students were motivated to get involved in the classroom activities.
\end{abstract}

Keywords: task-based instruction, grammatical performance, PPP, attitudes, speaking, writing

\section{INTRODUCTION}

Grammar has gained a lot of attention from English Language Teaching experts in the history of learning and teaching English as a foreign language (EFL). Grammar instruction is critical in every course, according to experts. Despite the importance of grammar in the language learning process, learners have found grammar to be the most difficult aspect to grasp (Sawir, 2005). As a result, it has become one of the most common issues encountered by EFL students. According to Shatz and Wilkinson (2010), second-language (L2) learners are normally unable to articulate their high-order thinking because they cannot generate complex sentences (2010).

According to Widdowson (1979), academic achievement in language usage can be traced back to teaching and learning. Various approaches to EFL learning and teaching

Citation: Pham, V. P. H., \& Do, T. H. (2021). The Impacts of Task-based Instruction on Students' Grammatical Performances in Speaking and Writing Skills: A quasi-experimental study. International Journal of Instruction, 14(2), 969-986. https://doi.org/10.29333/iji.2021.14255a 
have been applied and researched, as can be seen from EFL learning and teaching experience. Practitioners and students of English as a foreign language (EFL) have employed the Grammar Translation Method (GTM) or other methods relating to Communicative Language Teaching (CLT). The teachers usually employed pair-work and group-work to help students practice the language together (Pham, 2021) to sole the problem of large-size classes, from 40 to 45 students per class (Pham, 2019). The approach of Presentation-Practice-Production (PPP) is a framework for teaching grammar. While PPP was considered a useful teaching technique that was easy to follow and coordinate, it proved troublesome. According to Ellis (2003), students who are taught using the PPP model cannot communicate outside of the classroom, especially with native speakers. Despite the fact that PPP lessons provide skills, most students, according to Richards and Rodgers (2014), are unable to communicate effectively in English. In addition, a number of students have shown that they felt difficult to study grammar and that it is a kind of demotivating factor in their studies. Pham and Do (2019) have pointed out that many students struggle in their everyday situations in the Vietnamese context. Learning difficulties for students have become one of the first and foremost concerns in writing classrooms.

Task-Based Instruction (TBI) has piqued ELT experts' and teachers' attention, as it considers the idea that language learning must be integrated into real communication in which learners use language in practical ways (Nunan, 2004). However, it appears that many Vietnamese teachers are skeptical of this modern approach to education. Many of them, in particular, are familiar with conventional approaches such as GTM or CLT, as well as the PPP model, and find it difficult to move to a new approach. Furthermore, there has been little study in TBI in the Vietnamese context to date.

The researcher was motivated to research the impact of TBI on the grammar output of pre-intermediate non-English major students' speaking and writing skills at Van Lang University because of shortcomings in grammar teaching and interest in a new teaching approach. Aleksius et al. (2021) suggesed that TBI should be applied in the speaking classes to help improve the students communicative competence. Also, Derakhshan (2018) found that TBI helps students perform better.

\section{Task-based Instruction}

Task-based teaching is currently used in ELT classrooms and course books. It is part of the approach to communicative language instruction. There are differences in the way CLT has been applied. In short, the theorists suggested two variants of the CLT, the strong one and the weak one (Klapper, 2006). The latter is known to be the standard version of CLT since it has been implemented in a number of course-books and curricula. The Presentation-Practice-Production Model (PPP), as described by Ellis (2009), has long been a standard lesson structure for the bad edition. Meanwhile, Taskbased Instruction can be viewed as an evolution of a more powerful version of the CLT.

The concept of task-based instruction as a new offshoot type of the CLT (Klapper, 2006) has piqued interest in the field of ELT over the last two decades, especially in the strong version. It seems to have been introduced in response to the PPP paradigm's 
criticism. This strategy aims to adhere to Second Language Acquisition theories, which explain how English language learners acquire the language. TBI focuses on the idea that second-language learning necessitates working fluency first, then precision-focused activity.

\section{Framework for a Task-based Learning Lesson}

Klapper (2006) proposed a three-part framework for a task-based instructional lesson created by Willis (1998) as it is the most advanced and simple for teachers to employ.

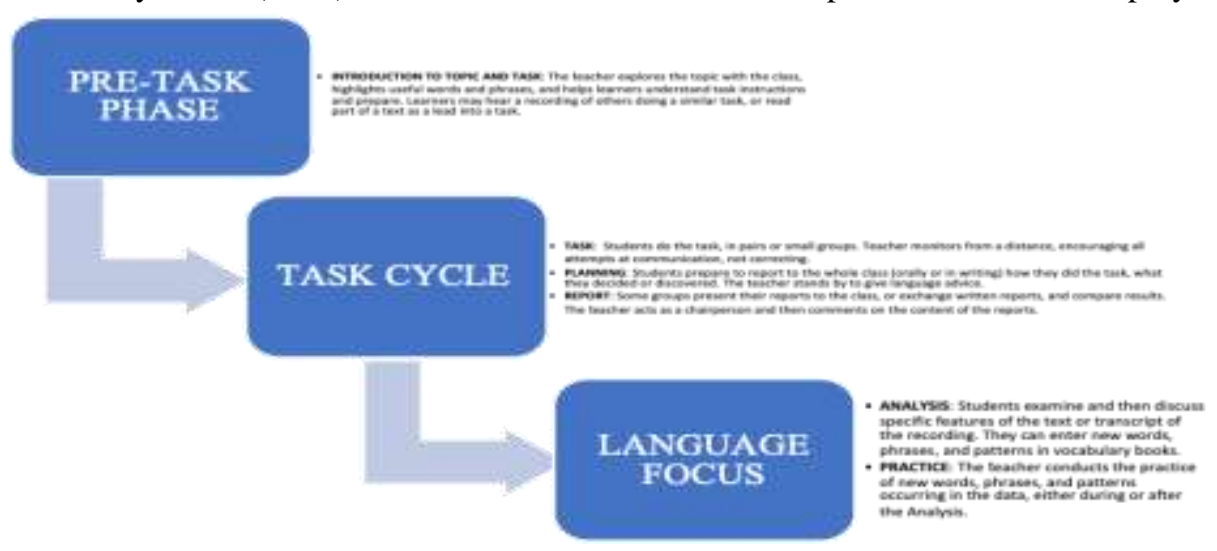

Figure 1

Task-Based Learning framework (Willis, 1998: 17)

\section{Merits and demerits of TBI}

According to Ellis (2009), TBI has a range of advantages while working in the classroom. In the TBI classroom, learners are given the chance of natural learning with associated real-world activities. It helps to enhance the communication skills of learners outside the classroom (Houghton, 2018). Meaning-focused learning is encouraged, whereas the form is often integrated into the activities. Skehan (1996) argued that the TBI aims to help learners gain fluency over the form while communicating meaning under time pressure to complete the tasks. TBI is often believed to increase learners' inner motivation rather than extrinsic motivation (Nunan, 2004) since it is a learnercentered motivation.

However, some difficulties remain for EFL practitioners. The TBI is known to be unacceptable for learners at all stages. In the absence of adequate linguistic support, TBI results in unequal oral growth, especially for beginners (Bruton, 2005 as cited in Klapper, 2006). Since they are not covered in textbooks, the meaning-focused tasks' raw data may be restricted (Hismanoglu \& Hismanoglu, 2011). TBI, therefore, demands a high degree of imagination on the part of teachers. There is also a need for further research to show the likelihood of achieving fluency over accuracy. Hismanoglu and Hismanoglu argued that relying on fluency over accuracy could be dangerous for learners. 
According to Ellis (2003), Skehan (1996), and Ellis (2009), TBI was successful in supporting second language acquisition. Many studies have shown that TBI has actually helped learners develop their grammar skills better than those who have studied in conventional classes. (Wang, 2019; NamazianDost, Bohloulzadeh, \& Pazhakh, 2017; Kafipour, Jafari, \& Khojasteh 2018; Marlina, 2014; Yildiz \& Senel, 2017; Tale \& Goodarzi, 2015). Besides, language performance such as speaking and writing skills of the students was improved significantly in TBI classrooms (Ahmed \& Bidin, 2016; Huang, 2016). Ahmed and Bidin (2016) indicated that the experimental group's students enhanced their complexity, fluency, and accuracy in writing skills. In particular, the experimental group made significant progress in their accuracy.

Pham and Nguyen (2014) investigated the effect of TBI on the speaking skills of the 1st year students. The researchers found out that the TBI has helped to develop students' speaking skills. In addition, the learners disclosed that they found TBI to be a strong method and that they were confidently participating in the oral classroom. However, the study had some limitations, such as the limited sample size (only 26 students) and the lack of English-speaking students. If the samples had one control group, the study could have been more robust in demonstrating the superiority of TBI over traditional methods.

Another remarkable Kasap (2005) conducted a study on the effectiveness of task-based learning in enhancing learners' ability to communicate. Research has attempted to investigate whether the TBI approach has outperformed the traditional PPP method in improving the language skills and expectations of this experimental method by teachers and students. The researcher used a mixed approach where pre-tests, post-tests, questionnaires, and interviews were the instruments to gather data. At the low intermediate stage, 45 students participated in this research. The results show that Between the control and experimental classes, there is no statistically significant difference. However, the qualitative data showed positive instructor and student reflection after learning it. In particular, students showed neutral or positive attitudes. They generally felt they enhanced their abilities.

The task is focused on Training also inspired Marlina (2014) to undertake action research to enhance student grammar mastery. The research aim was to investigate whether TBI could improve the grammar mastery and classroom condition of students. Study participants include 41 English degree students with poor grammar mastery. The researcher used a broad range of testing tools, including grammar tests, questionnaires, observation sheets, and dairy instructors. Results indicated that the students' grammar mastery improved after the TBI approach intervention. They are particularly adept at understanding and applying grammar in context. To put it another way, grammar can be used in both speaking and writing. When the students were more inspired and engaged in the lesson, they displayed a better attitude.

Huang (2016) conducted action research in a comprehensive Chinese English class in order to learn more about the effectiveness of TBI on student language skills and attitudes toward its implementation. Questionnaires, interviews, classroom evaluations, and a teaching journal were among the researcher's data collection methods. The results supported TBI's positive impact on student language learning, including speaking and 
writing skills. In terms of student reflections, the results indicated that TBI improved their motivation by significantly enhancing their interest in English, enjoyment, learning autonomy.

NamazianDost et al. (2017) conducted a survey of 80 pre-intermediate students. The Control group and experimental group were randomly chosen. Students received conventional training through examples or exercises in the control group. TBI was included in the experimental community. The post-test repeated the pre-test to assess students' grammar learning advancement and validate TBI's efficacy. The results revealed that the study group's learners performed better than the others. The study aims, therefore, only to analyze grammar performance utilizing grammar tests. There is, therefore, a further need to explore the effects of TBI on the grammar performance of students in speech and writing.

In Turkey, Yildiz and Senel (2017) examined the impact of TBI on young learners' grammar skills. The researchers concluded that, while both the control and experimental groups strengthened their grammar knowledge as a result of the learning process, after the study at the end of the teaching period, there was a significant difference in the aftertest between the two classes, with the latter getting more benefits. In addition, the TBI classroom had a more inspiring and stimulating learning experience than the other classrooms.

Kafipour et al. (2018) conducted the latest study on TBI's impact on motivation and grammar learning at a high school in Iran. The study participants are 66 elementarylevel male students. The students were assigned two groups, 33 for the experimental group and the other 33 for the control group. The Nelson test was used to ensure homogeneity prior to treatment, rather than picking people at random. Nelson's motivation questionnaire and a grammar test are included in the pre-test. The control group outperformed the experimental group in this study, which was consistent with previous studies regarding the important effects of TBI on EFL students. The morale of experimental students was extremely high.

Despite the fact that the majority of studies have found benefits to Task-based instruction in grammar instruction, Baleghizadeh and Ghobad (2012) discovered that teaching grammar using TBI was no better than teaching grammar using the conventional PPP model. In this analysis, 56 students from two Iranian universities were at the beginner proficiency standard. The PPP training model was used by two teams, while the other two groups were exposed to TBI. Pre-test, post-test, and observation were among the instruments used by the researcher. The findings revealed that both groups progressed at the same pace.

\section{Research gaps}

Briefly, most previous studies positively affect TBI on grammar teaching and learning (Kafipour et al., 2018; NamazianDost et al., 2017; Yildiz and Senel, 2017; Huang, 2016; Tale \& Goodarzi, 2015; Marlina, 2014). The most popular tool for measuring TBI's efficacy relative to other conventional approaches is pre/post-testing. However, it is noteworthy that some studies display findings that do not fully agree with the above 
analysis. Some researchers (Yi \& Pham, 2018; Baleghizadeh \& Ghobad, 2012; Kasap, 2005) have argued that The TBI method cannot be more efficient than other conventional approaches. In terms of learner perceptions, though some quantitative evidence (Kasap, 2005; Baleghizadeh and Ghobad, 2012) showed that TBI did not outperform other approaches, the majority of studies revealed that learners had positive attitudes toward the TBI approach. However, as Ji and Pham pointed out, TBI still has some issues with student participation in the classroom (2018).

In addition, there is little research into the effect of TBI on the performance of grammar learners in speaking and writing, as can be seen in the field of grammar education via TBI as a measure of language assessment. In response, the researcher decided to examine how the TBI approach influenced the grammatical success in speech and writing examinations of the pre-intermediary non-English major students. These gaps were closed, and the following research questions were answered in current research:

1. To what extent does TBI impact the pre-intermediate non-English-majors' grammatical performance in their speaking skills?

2. To what extent does TBI impact the pre-intermediate non-English-majors' grammatical performance in their writing skills?

\section{METHOD}

\section{Research Setting and Participants}

The research was carried out at Van Lang University (VLU) in Ho Chi Minh City, Vietnam. VLU offers courses and programs, which include the B.A. in thirty fields of study and seven programs in Master's Degrees, which are officially accepted. Students arrived from all over Vietnam, with the majority hailing from the country's southern provinces. A total of 17,000 students were enrolled, with about 5,000 full-time students per intake. Students enrolled in the VLU training program were required to complete four semesters of English at the following level: English 1, English 2, English 3, and English 4 are the four languages that make up the English language. Students were required to pass the final exam with a score of at least 4.5 in order to advance to the next level, such as from A1 to A2.

The teacher/researcher was assigned two intact classes of first-year students who were non-English majors. The two intact classes were randomly assigned to a control group and an experimental group. Fifty-nine $1^{\text {st }}$ year students from the two intact classes assigned to the researchers, 30 from the experimental group, and 29 from the control group participated in the study. Their ages ranged from $19-20$ years old. The experimental group had 11 male and 19 female students, and the control group had four males and 25 females. The majority of them had spent seven years in high school studying English. They came from a variety of provinces and cities in Vietnam, the majority of which were in the south. They all passed the first semester's final exam, which was a prerequisite for enrolling in the English-2 course.

The class structure was determined before the semester. It relied on the random enrolment of the students due to the credit regulations. The researcher conveniently 
picked two intact-classes out of six assigned classes at Van Lang University to carry out the experiment. This is because the other four classes completed half of the semester and were unable to participate in the experiment. One class (29 students) served as the control group and received standard PPP instruction; the other (30 students) served as the experimental group and learned grammar using Task-based instruction.

The current study employed a quasi-experimental study. Quantitative data with numerical statistics were collected using pre- vs. post-test, and the qualitative data were collected from the semi-structured interviews. As a result, the analysis approach was mixed-method, which is a mixture of quantitative and qualitative approaches.

\section{Instruments}

Pre-test and Post-test: The students' level in grammatical performance was measured through the pre-test and post-test. The Cambridge Key English Test (2004) was used as the basis for this experiment's pre-test. It was designed for students at the preintermediate level (A2) and included interest and school experience topics. In the pretest and post-test, two parts were included: Part 1, Part 2, and the following shall be addressed:

- Part 1: A guided writing test from the Cambridge English Language Assessment's Main English Test (KET) was chosen to assess the students' ability to use grammar in writing. This section required students to write a letter or a postcard in 20-35 words. The exam took ten minutes to complete.

- Part 2: The students' performances in the speaking test were reported on the smartphone for later evaluation. The test had two parts and lasted 15 minutes. The Post-test has the same format as the Pre-test.

Interviews: This study employed semi-structured interviews to collect qualitative data. Twenty students, ten from each group, were randomly selected for the interviews. The interviews were conducted after the lesson of each class meeting. Each time, two students attended the interviews in the classroom. Each interview was between 20 and 30 minutes long. With the interviewees' permission, the interviews were recorded on the phone. The students were asked to determine (1) their interpretation of the lesson, (2) their preferences for the method of TBI, (3) their suitability level, (4) the difficulties they faced during their mission, and (5) their expectations and/or suggestions for improving the teaching process.

\section{Scoring Rubrics}

The assessment scale was used to test the ability of students to use proper grammar in their language and writing. It has been adapted from the A2 Teachers' Main Handbook for 2020 examinations (Cambridge English Qualifications, 2018). 
Table 1

Grammatical performance assessment scales in writing and speech

\begin{tabular}{ll}
\hline Band scales & Description of grammar usage \\
\hline 5 & Demonstrates a high level of command over basic grammatical forms. \\
\hline 4 & Bands 3 and 5 are represented in the performance. \\
\hline 3 & Demonstrates adequate command of basic grammatical forms. \\
\hline 2 & Bands 1 and 3 have similarities in their performances. \\
\hline
\end{tabular}

The current study employed two raters to mark students' speaking and writing performance. One rater is the researcher. The other is one of her colleagues at Van Lang University, who gained a MA in TESOL and has more than ten years of teaching experience. The Cronbach's Alpha of the writing pre-test, writing post-test, speaking pre-test, and speaking post-test were $.765, .755, .892, .822$. The results of Cronbach's Alpha indicate the reliability of the marking of the test scores. The scores were finalized as the average of the scores marked by the two inter-raters to ensure consistency.

\section{Research procedure}

The study began in the second month of the second semester and lasted for eight weeks, with five grammar lessons. There were five grammatical subjects mentioned on the syllabus: Must, Might-May-Will (probably), Conditional sentences, such as Zero Conditional and First Conditional, and Present continuous for future use. It was noteworthy that during the first month of the semester, prior to treatment, both groups of students learned grammar using the same conventional approach, PPP. In general, the study had three phases: participant selection and pre-test administration, treatment implementation, and post-test administration.

Phase 1: At the start of the treatment, the researcher chose two pre-intermediate classes, each with 59 students, to serve as the control and experimental groups. Following that, the two groups were given a pre-test to ensure that they were homogeneous.

Phase 2: The two groups went through the same content. The control group instructor used the PPP model, while the experimental group used TBI to study grammar.

Phase 3: The researcher conducted a post-test after eight weeks of treatment. The format and method of the post-test were identical to those of the pre-test.

\section{Training Procedure}

The training procedures of the control group (PPP) were illustrated in Fig. 2. All the activities were repeated in every class meeting. 
Figure 2

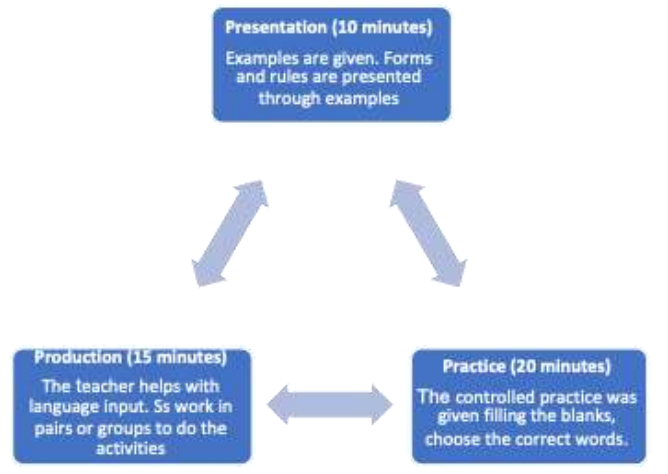

The training procedure for PPP model (control group)

The training procedures of the experimental group (TBI) were illustrated in Fig. 3.

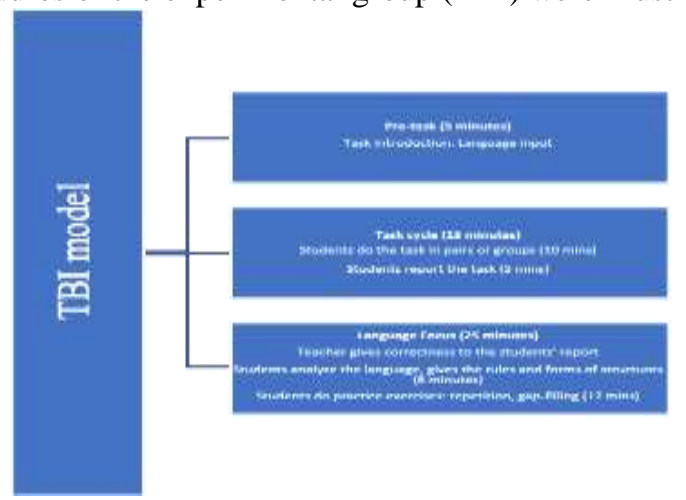

Figure 3

The training procedure for the TBI model (Experimental group)

\section{FINDINGS AND DISCUSSION}

Until presenting the study's findings in response to the two research questions, the results of the students' pre-tests were examined to see whether there were any discrepancies in their speaking and writing abilities before the treatments. The scores were finalized as the average of the scores marked by the two inter-raters to ensure consistency. The Cronbach's Alpha of the writing pre-test was .765 , and the speaking pre-test was .755 . It indicated that the scores of the students reached reliability for analysis. Table 2 presents the results of the students' writing skills of the two groups in the pre-test.

Table 2

Independent samples t-test of speaking pre-test

\begin{tabular}{llllllll}
\hline & Group & $\mathrm{N}$ & Mean & Std. Deviation & $d f$ & $t$ & $p$ \\
\hline \multirow{2}{*}{ Speaking pre-test } & TBI & 30 & 2.82 & .549 & 57 & -1.422 & \multirow{2}{*}{160} \\
\cline { 2 - 8 } & PPP & 29 & 3.03 & .625 & & & \\
\hline
\end{tabular}


Table 2 shows that students of the test group scored slightly higher in the pre-test speaking group than students of the (TBI) experimental group (Mean $=3,03$ vs. Mean $=$ 2,82 , respectively), but the experimental group (TBI) sig ( 2 tailed) $p=, 160>5$ percent pointed out that the average score of these two groups did not differ from that of the experimental group (TBI). It indicates that the students in both groups spoke with the same degree of grammatical proficiency. The SD (.549 and.625) value 1 is another interesting statistic number. It indicates that their skill levels were almost identical. The study should certify the null hypothesis based on the above findings; in other words, the study ensured that the two groups' grammatical output was homogeneous. As a result, the experiment met the criteria and was approved for implementation.

Table 3

Independent samples t-test of writing pre-test

\begin{tabular}{llllllll}
\hline & Group & $\mathrm{N}$ & Mean & Std. Deviation & $d f$ & $t$ & $p$ \\
\hline \multirow{2}{*}{ Writing pre-test } & TBI & 30 & 2.63 & .556 & & & \multirow{2}{*}{.973} \\
\cline { 2 - 8 } & PPP & 29 & 2.64 & .498 & 57 & -.33 & \multirow{2}{*}{ P. } \\
\hline
\end{tabular}

Table 3 indicates that the control group (PPP) was in excess of the experimental group (TBI) in the writing test $(\mathrm{M}=2.63$ vs. $\mathrm{M}=2.64)$. The sig (2-tailed) $\mathrm{p}=.973>$ alpha $(5$ percent) implies no statistical difference in ratings between the two classes. It means that both classes were equally capable of using grammar in literature. Furthermore, the fact that the dispersion of the students' scores in each category was not high (1) showed that their level was homogeneous within one marking scale. Table 3 shows the pre-test outcomes for the two classes of students' speaking abilities.

Research question 1: To what extent does TBI impact students' grammatical performance in speaking skills?

To address this research question, paired sample t-tests were used to compare the preand post-test results of the two groups to see whether there were statistically relevant variations in the students' oral performances. After that, the researchers ran the independent sample t-tests to see if the two groups' post-tests were statistically different. If yes, the null hypothesis was rejected.

\section{Comparison of the speaking pre-test \& speaking post- test}

Table 4

The pre- vs. post-tests of speaking skills of the TBI \& PPP group

\begin{tabular}{lllllllllll}
\hline \multicolumn{1}{c}{ TBI } & \multicolumn{10}{c}{ PPP } \\
\hline & Mean & $\mathrm{N}$ & SD & $t$ & $p$ & Mean & N & SD & $t$ & $p$ \\
\hline Speaking pre-test & 2.82 & 30 & .549 & \multirow{2}{*}{-15.50} & .000 & $\frac{3.03}{3}$ & 29 & .625 & -10.39 & .000 \\
Speaking post- test & 3.73 & 30 & .537 & & & 3.74 & 29 & .510 & & \\
\hline
\end{tabular}

As shown in Table 4, both groups improved their grammatical performance in the speaking test after receiving treatment. In more depth, the TBI community received an average score of 3.73 , which was significantly higher than the mean score of 2.82 in the pre-test for their grammar use. In addition, students in the PPP category scored 3.74 on the pre-test, compared to 3.03 on the pre-test. The statistic p-value (sig 2-tailed) $=.000$ 
$5 \%$ in the two paired samples t-tests unmistakably showed a statistical discrepancy between the two groups' pre-test and post-test. The scores 2.82 and 3.03, in particular, correspond to a scale of 2 to 3 on the labeling scales. It indicates that the students had a fair command of basic grammatical forms prior to treatment. However, most of them earned about 3.73 to 3.74 in the post-test, which is nearly equal to 4 . The students were expected to be able to control basic grammatical forms reasonably well on this scale.

\section{Comparison of The TBI and PPP groups' speaking post-tests}

Table 5

The speaking post-tests of the TBI group and PPP group

\begin{tabular}{lllllll}
\hline & Group & $\mathrm{N}$ & Mean & Std. Deviation & $t$ & $p$ \\
\hline \multirow{2}{*}{ Speaking post- test } & TBI & 30 & 3.73 & .537 & -.059 & .953 \\
\cline { 2 - 8 } & PPP & 29 & 3.74 & .510 & & \\
\hline
\end{tabular}

Table 5 compares the students' grammatical output in the speaking post-test to their mean scores. The PPP group students performed marginally better in the post-speaking examination than the TBI group students. In particular, for their grammar use, the PPP group obtained an average of 3,74 compared to 3,73 for the TBI group. However, the two p-value classes of 0,95 have not been statistically significantly differed. The results showed that the TBI group did not outperform the PPP group by increasing students' grammatical use in their language. Taking into account each approach's single-stage, it's clear that the students in both groups received adequate form- and meaning-focused activities. The protocol of the phases in a lesson was the distinction between the treatments for the two classes. The results of this study corresponded to Kasap (2005)'s who found no difference between the control and experimental group. However, both the students and the teacher obtained a positive experience with this study's results. Similarly, Baleghizadeh and Ghobad (2012) also found no different improvements between the two groups. However, the results of this research do not appear to be consistent with those of previous studies (Pham \& Nguyen, 2014; Kasap, 2005), in which the TBI was shown to help learners outperform those who were trained using conventional methods in their speaking. Marlina (2014) and Huang (2016) discovered that students understand how to use grammar in meaning and can use it in both speaking and writing. The findings of the current study also corresponded to Houghton's (2018) that IBT was a means to improve students' communicative skills not only inside but also outside the classroom since the students practiced the tasks with meaningful focus. Hence, the students could produce the language more fluently (Skehan, 1996).

According to the semi-structured interviews, 10/10 of the experimental group (TBI) students said they understood the grammar point posed in the lessons. This achievement may be attributed to the students' exploration of the grammatical point in the light of their own desires and experiences. Furthermore, the teacher was instrumental in assisting them with language analysis. As a consequence, they know what to use, how to use it, and when to use it. A range of best practices was also presented to ensure consistency. 
The new approach was, at first, very frustrating because I know the existing one. However, it has helped me to see the variations in any grammatical structure because of the activities. The task helped us to understand the lesson and to understand the grammar point better [S1].

As a whole (9/10), the PPP group said they understood the grammatical points discussed in the class. Only one of them said that she only "partially comprehends." When asked why she found the lesson so difficult to grasp, the student admitted that it was because:

"I'm having difficulty concentrating on the first session of the lesson, where the teacher provided examples and clarified the grammatical point. There seem to be a number of different systems to master. " [S3]

Although the student did not expand on why she was unable to concentrate on the lesson, it seems that the process of presentation before rehearsal and development made the lesson too boring for her to pay attention to the teacher's instructions.

Both approaches proved to be successful, as evidenced by the students' opinions on the level of their understanding of the grammar lesson. The TBI, on the other hand, seemed to be the students' latest instructional form. Some students may have been perplexed for the first time. However, the later lessons were extremely effective and beneficial to the students. The student in the PPP school, on the other hand, missed the lesson because she didn't pay attention to the teacher's presentation.

It's worth noting that all of the TBI students (10/10) agreed that the tasks were engaging and interesting and actively engaged in the mission. The following excerpts show their responses.:

We work as a group, and the challenge seems to encourage us to collaborate and compete with other teams to complete the tasks. Today's subject (global warming) is very relevant; I know a little about it and am interested in it, so I'd like to include it in my team. [S3]

Three students in the PPP group, on the other hand, admitted that they didn't participate in the activities very much. The other two students had the same motivation as the above student: they only wanted to get out of class after an hour of studying the structure.

I'm used to the grammar explanations because I've been through them before. However, it appears that the systems need more examples and scenarios in order to be more understandable. After a long lecture, I just want to get home, so I'm not interested in participating in the activity at the end... [S7]

The majority of students in the TBI group (9/10) said the tasks were suitable for their level. Only one student in the first lesson reported having difficulty using language, especially vocabulary while completing the assignment, as seen in the excerpt below:

I believe I had difficulty finding words for communicating because we had to complete the assignment right at the start of the class. Before starting the job, I believe the instructor should have more vocabulary. [S2] 
The students had the above problem in terms of a lack of language to complete the assignment, so the researcher could allow them to use a dictionary in groups if possible. In the following classes, the instructor also gave more specific information to the students.

One of the study's primary objectives is to see whether students are interested in the new procedure. According to many studies, motivation is critical in the long-term learning phase of students (Ushioda, 2009). It will determine whether they can study or not, how much effort they put in, and how good they are at learning. Interviews are held after each lecture, and the results are astounding. All students (10/10) said that they chose the TBI approach and decided to use this new approach to learn grammar. The interview is described in-depth in the following extracts:

This new approach appeals to me better. Since we complete the task prior to reviewing the grammar, this approach is more engaging than the previous method, which included a dull presentation. We had more opportunities to train. [S9]

The findings back up previous research by Huang (2016) and Kafipour et al. (2018), who discovered that the TBI is stated to be a motivational process.

According to the data collected from the interviews, the majority of students in the PPP group (6/10) showed little interest in current grammar teaching and learning, as seen in the excerpts below:

The first section of the lesson is a little tedious, and I'm finding it difficult to focus because there are so many examples and structures. [S9]

Just 4/8 of them said they "are familiar with this approach" and that "we also have activities to do group work to improve speaking skills, so I find it interesting." I just did lessons while I was in high school for grammar." As can be shown, the PPP is still effective for them since this approach appears "new" to those who have previously learned grammar using a traditional method such as the Grammar Translation Method.

Since each teaching technique has its own set of strengths and limitations, there is no one-size-fits-all approach that will work with every learner in every class (Lambert, 2004). TBI also tends to be a form that the students have never encountered before. As a result, it is critical to investigate any challenges that participants may be experiencing and their aspirations to enhance teaching and learning.

When the researcher asked the TBI students if they had any issues, they revealed that they had two major challenges: group work and weak grammar and vocabulary. As seen in the following extracts, some of the participants (2/10) found it difficult to collaborate with their colleagues during group work tasks:

Working in a group is very difficult for me. My colleagues refused to work with me. Occasionally, I feel as if I've been abandoned. [S17]

In summary, all of the TBI students said that they were engaged and inspired in the learning process. As a result, they were more engaged in the activities. The results are 
consistent with Huang (2016) and Marlina's study (2014). The students in this study said they were tired of listening to grammar explanations and were inspired by the new process (TBI). This finding refuted Pham et al. (2020)'s argument that Vietnamese students were uninterested in learning to write. The findings support previous research (Marlina, 2014; Tale \& Goodarzi, 2015; Huang, 2016), which found that TBI has a major effect on students' motivation. The current findings corroborated Nunan's (2004) argument that IBT increased students' motivation in the learning process as they completed tasks in the classroom. On the contrary, some students in the PPP community expressed disinterest in the lessons due to a large number of structures to understand. These results corroborated previous research by Kafipour et al. (2018), Yildiz and Senel (2017), NamazianDost, et al. (2017), Huang (2016), and Tale and Goodarzi (2015), Marlina (2014) in which learners demonstrated high motivation engagement while learning through TBI versus other methods.

Research question 2: To what extent does TBI impact students' grammatical performance in writing skills?

The researchers used a paired sample t-test to compare the two groups' pre- to post-test results and see if there were any differences between the two groups' pre-and post-test results in order to address this research query. The outcomes of the two groups' posttests were then compared using an independent-sample t-test to see whether there were any statistically relevant variations.

\section{Comparison of the writing pre-test \& writing post-test}

Table 6

Writing pre-test and writing post-test of the two groups

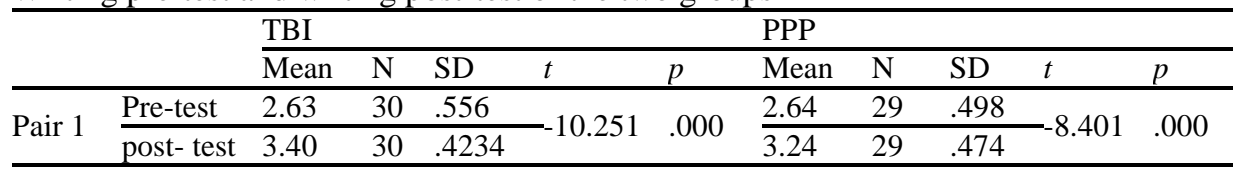

Table 6 shows the results of the paired samples t-tests of the two groups' grammatical output in the writing pre-and post-tests. The two groups showed similar changes in proper grammar use in their writing tests as they did in their speaking tests. Students in the TBI group scored 3.4 on the writing post-test for grammatical performance, compared to 2.63 on the writing pre-test. The results indicated that the pre-test and posttest in the TBI classes were statistically significant differences, as shown by the p-value (p.05). In other words, the students' productive skills in writing performances in the TBI group remarkably enhanced after receiving the Task-based instruction.

Similarly, the PPP students had greater grammatical use in their post-test writing (Mean score $=3.24$ vs. Mean score $=2.64$, respectively). The p-value (p.05) suggests that after the treatment, the students had a greater understanding and practical application of grammar. The post-scores that shared features with bands 3 and 4 indicated that they had reasonable and often excellent grammar control. 


\section{Comparison of the writing post-test}

Table 7

Independent samples t-test of writing post-test

\begin{tabular}{ccccccc}
\hline & Group & $\mathrm{N}$ & Mean & Std. Deviation & $t$ & $p$ \\
\hline Writing post- test & TBI & 30 & 3.40 & .423 & 1.355 & .181 \\
\hline PPP & 29 & 3.24 & .474 & & \\
\hline
\end{tabular}

Table 7 compares the mean scores of the TBI and PPP classes. There was a slight difference as the TBI group's Mean score of 3.40 was higher than the PPP group's $($ Mean $=3.24)$. The independent sample t-test $\mathrm{p}$-value $=.181, \mathrm{p}>.05$, however, revealed that there was no statistical difference between the two classes. This finding was not surprised to previous researchers such as Kasap (2005) and Baleghizadeh and Ghobad (2012) when the two groups made progress equally. There could be some explanations for these findings. First, in the PPP method, equal attention was paid to the presentation of language features and the language analysis. Second, both models offered adequate control practice to assist students in practicing the forms. The PPP approach, which included plenty of practical activities to help learners produce the language in context, was the third stage of development. This stage had many of the same characteristics as the tasks used in the TBI method. In case the researchers paid equal attention to the training of the two groups, both TBI and PPP teaching models had great impacts on the students' productive skills. However, the findings of the current study yielded great arguments to some previous researchers such as Pham and Nguyen (2014), Marlina (2014), Tale and Goodarzi (2015), Ahmed and Bidin (2016), Huang (2016), NamazianDost, et al. (2017), Yildiz and Senel (2017), Kafipour, Jafari, and Khojasteh (2018), and Wang (2019) who found that TBI helped students improve their writing skills much better than the PPP. The current study raised a new issue that whether TBI had significant effects on the students' speaking and writing skills as claimed by previous researchers'.

\section{CONCLUSION}

The study's purpose was to enhance current teaching practices using the conventional PPP approach. First, the current study's post-test results showed that the students' grammatical performance in speaking of the experimental group (TBI) was statistically significant and different from their pre-test results. It indicates that the TBI had great impact on students' grammatical performances in speaking skills. In this aspect, however, there was no statistical difference between the experimental and control groups. In other words, the TBI model did not outperform the PPP model in teaching students' grammatical performance in speaking skills. Second, the study's findings showed that the TBI model significantly affected students' writing grammatical efficiency. Although the experimental group's mean score was higher than the control group's (3.40 vs. 3.24), the TBI model did not outperform the PPP model in terms of students' grammatical success in writing skills. The findings of the current study indicate that through either TBI or PPP teaching model, with the instructor's great care, the students' grammatical performances in both speaking and writing skills improved. However, apart from the grammatical performances, the employment of the TBI model 
was recommended to the language teachers because it was not, at least, less efficient when training students on how to use grammar in their productive skills compared with the traditional methods (PPP), and the students had many chances to practice the language in the grammar classrooms. The qualitative data revealed that the students preferred the TBI to PPP because it actively motivated them to engage in the learning process.

The researcher acknowledged some limitations of this analysis, including the task design and the limited qualitative data, in order to strengthen her current language teaching practice. The instructor, in particular, struggled to locate credible texts or recordings of fluent speakers performing the same tasks. Furthermore, textbook designers should consider including more similar activities in the coursebook to reduce teachers' workload. Task-based learning can also be used as an alternative instructional tool for teachers.

\section{REFERENCES}

Aleksius, M., Widiati, U., Suharmanto. \& Prayogo, J. A. (2021). Task-Based Assessment in Using Other-Initiated Repair Strategies of the Pre-Service EFLTeachers. International Journal of Instruction, 14(1),761778.https://doi.org/10.29333/iji.2021.14146a

A2 Key Exam Format (2019). Cambridge Assessment English. Retrieved August 20, 2019 from https://www.cambridgeenglish.org/exams-and-tests/

A2 Key Handbook for Teachers for exams from 2020 (2018). Cambridge Assessment English. Retrieved August 20, 2019. Retrieved from https://www.cambridgeenglish.org/pl/Images/504505-a2-key-handbook-2020.pdf

Ahmed, R., \& Bidin, S. (2016). The effect of task-based language teaching on writing skills of EFL learners in Malaysia. Open Journal of Modern Linguistics, 6(3), 207-218. DOI: $10.4236 /$ ojml.2016.63022

Baleghizadeh, S., \& Ghobadi, S. (2012). The effect of teaching grammar through the task-supported structural model on EFL learners' grammatical achievement. Journal of Theory and Practice in Education, 8(2), 1-18.

Cambridge ESOL. (2004). Cambridge Key English Test 1 Self Study Pack: Examination Papers from the University of Cambridge ESOL Examinations (Vol. 1). Cambridge University Press.

Derakhshan, A. (2018). The Effect of Task-Based Language Teaching Instruction on the Iranian Intermediate EFL Learners' Writing Performance. International Journal of Instruction, 11(4), 527-544.https://doi.org/10.12973/iji.2018.11433a

Ellis, R. (2003). Task-based language learning and teaching. Oxford: Oxford University Press.

Ellis, R. (2009). Task-based language teaching: Sorting out the misunderstandings. International Journal of Applied Linguistics, 19(3), 221-246. 
Hismanoglu, M., \& Hismanoglu, S. (2011). Task-based language teaching: What every EFL teacher should do. Procedia-Social and Behavioral Sciences, 15, 46-52. DOI: https://doi.org/10.1016/j.sbspro.2011.03.049

Houghton, L. (2018). The strengths and weaknesses the Task-based syllabus. Retrieved on February $4^{\text {th }} 2019$, from https://www.birmingham.ac.uk/Documents/collegeartslaw/cels/essays/sylabusandmaterials/Houghton-The-strengths-and-weaknesses-ofthe-task-based-syllabus-Luke-Houghton.pdf

Huang, D. (2016). A study on the application of task-based language teaching method is a comprehensive English class in China. Journal of Language Teaching and Research, 7(1), 118-127. DOI: http://dx.doi.org/10.17507/jltr.0701.13

Kafipour, R., Jafari, S., \& Khojasteh, L. (2018). The effect of task-based instruction on L2 grammar learning and motivation of Iranian EFL learners junior high school students. Revista Publicando, 5(16), 746-795.

Kasap, B. (2005). The effectiveness of task-based instruction in the improvement of learners' speaking skills, Doctoral dissertation, The Institute of Economics and Social Sciences Bilkent University, Ankara, Turkey.

Klapper, J. (2006). Understanding and developing good practice: Teaching languages in higher education. CILT, the National Centre for Languages.

Lambert, D. (2004). Teaching that makes a difference: How to teach for holistic impact. Michigan: Zondervan.

Marlina, N. (2014). The implementation of task-based language teaching to improve students' grammar mastery. (Master thesis, Sebelas Maret University, 2014). Retrieved from http://.digilib.uns.ac.id

NamazianDost, I., Bohloulzadeh, G., and Pazhakh, A. (2017) The Effect of Task-Based Language Teaching on Motivation and Grammatical Achievement of EFL Junior High School Students. Advances in Language and Literary Studies, 8 (2), pp. 243-259. DOI: http://dx.doi.org/10.7575/aiac.alls.v.8n.2p.243

Nunan, D. (2004). Task-based language teaching. Cambridge University Press.

Pham, P. V. H., Phung, L. T. K., Oanh, T. T. T., \& Giao, N. Q. (2020). Should Peer EComments Replace Traditional Peer Comments? International Journal of Instruction, 13(1), 295-314. https://doi.org/10.29333/iji.2020.13120a

Pham, V. P. H., \& Nguyen, T. B. (2014). The effects of communicative grammar teaching on students' achievement of grammatical knowledge and oral production. English Language Teaching. 7(6), 74-86. DOI: 10.5539/elt.v7n6p74

Pham, V. P. H., \& Do, T. P. T. (Dec. 2019). High School Students' Common Errors in Writing Essays. International Journal of English Linguistics, 9(6), pp. 309 - 319 (ISI/ESCI).DOI: 10.5539/ijel.v9n6p309 
Pham, V. P. H. (2021). The Effects of Collaborative Writing on Students' Writing Fluency: An Efficient Framework for Collaborative Writing. SAGE Open, 11(1), pp. 111. DOI: https://doi.org/10.1177/2158244021998363

Pham, V. P. H. (2019). The Effects of Lecturer's Model e-comments on Graduate Students' Peer e-comments and Writing Revision. Computer Assisted Language Learning, In press: 09 Jul 2019, Taylor \& Francis production (SSCI/ScopusQ1), https://doi.org/10.1080/09588221.2019.1609521

Richards, J. C., \& Rodgers, T. (2014). Approaches and methods in language teaching 3rd edition. Cambridge: Cambridge University Press.

Sawir, E. (2005). Language difficulties of international students in Australia: The effects of prior learning experience. International Education Journal, 6(5), 567-580.

Shatz, M., \& Wilkinson, L.C. (2010). The education of English language learners: Research to practice. New York: The Guilford Press.

Skehan, P., (1996). Second language acquisition research and task-based instruction. Readings in Methodology, 3, 13-23, from Willis, J. and Willis, D. (1996). Challenge and Change in Language Teaching. Heinemann

Tale, S. M., \& Goodarzi, A. (2015). The impacts of task-based teaching on grammar learning by Iranian first grade high school students. International Journal of Applied Linguistics and English Literature, 4(4), 144-153. DOI: http://dx.doi.org/10.7575/aiac.ijalel.v.4n.4p.144

Ushioda, E. (2009). A person-in-context relational view of emergent motivation, self and identity. In Z. Dornyei \& E. Ushioda (Eds.), Motivation, language identity and the L2 self (pp. 215-228). Bristol: Multilingual Matters.

Wang, S. (2019). The application of task-based approach in English grammar teaching in Junior High Schools. Journal of Language Teaching and Research, 10 (2), 304-310. DOI: http://dx.doi.org/10.17507/jltr.1002.12

Widdowson, H. G. (1979). Directions in the teaching of discourse. Oxford: Oxford University Press.

Willis, J. (1998). Task-based learning: What kind of adventure. The Language Teacher, 22(7), 17-18.

Ji, Y., \& Pham, T. (2020). Implementing task-based language teaching (TBLT) to teach grammar in English classes in China: using design-based research to explore challenges and strategies. Innovation in language learning and teaching, 14(2), 164-177.

Yildiz, M., \& Senel, M. (2017). Teaching grammar through task-based language teaching to young EFL learners. The Reading Matrix: An International Online Journal, 17(2), 196-209. 